\title{
Temporal echocardiographic assessment of pulmonary hypertension in idiopathic pulmonary fibrosis patients treated with nintedanib with or without oxygen therapy
}

Masahiro Tahara ${ }^{1 \dagger}$, Keishi Oda ${ }^{1 \dagger}$, Kei Yamasaki ${ }^{1}$, Takako Kawaguchi ${ }^{1}$, Konomi Sennari ${ }^{1}$, Shingo Noguchi ${ }^{1}$, Noriho Sakamoto ${ }^{2}$, Toshinori Kawanami ${ }^{1}$, Hiroshi Mukae ${ }^{2}$ and Kazuhiro Yatera ${ }^{1 *}$ (D)

\begin{abstract}
Background: Nintedanib is an inhibitor of receptor tyrosine kinases, including vascular endothelial growth factor receptor, but its effects on pulmonary hypertension (PH) in idiopathic pulmonary fibrosis (IPF) patients with chronic hypoxia were unclear.

Methods: This study included a nintedanib prospective study and historical control study. In the nintedanib prospective study, pulmonary artery systolic pressure (PASP) measured using transthoracic echocardiography was evaluated at six points during 48 weeks in 16 IPF patients in whom nintedanib was started. In the historical control study, adjusted annual change in PASP was compared between patients treated with $(n=16)$ and without $(n=15)$ nintedanib.

Results: In the nintedanib prospective study, the mean PASP at 48 weeks after starting nintedanib was significantly higher compared to that at baseline. When IPF patients were divided into two groups, IPF patients with or without long-term oxygen treatment (LTOT), mean PASP at 48 weeks was significantly higher than that at baseline only in IPF patients receiving LTOT $(P=0.001)$. In the historical control study, adjusted annual change in PASP in IPF patients treated with nintedanib was significantly lower than that in patients treated with no antifibrotic agents when considering patients without LTOT $(0.26 \mathrm{mmHg}$ vs $7.05 \mathrm{mmHg} ; P=0.011)$.

Conclusions: We found differential effects of nintedanib on PH between IPF patients with or without LTOT. Nintedanib may have a disadvantageous effect on PH in IPF patients with LTOT. Conversely, nintedanib treatment may be beneficial to PH in IPF patients without LTOT.
\end{abstract}

Keywords: Echocardiography, Idiopathic pulmonary fibrosis, Long-term oxygen therapy, Nintedanib, Pulmonary hypertension

\footnotetext{
*Correspondence: yatera@med.uoeh-u.ac.jp

${ }^{\dagger}$ Masahiro Tahara and Keishi Oda contributed equally to this work.

${ }^{1}$ Department of Respiratory Medicine, University of Occupational and Environmental Health, Japan, 1-1 Iseigaoka, Yahatanishiku, Kitakyushu city, Fukuoka 807-8555, Japan

Full list of author information is available at the end of the article
}

\section{Background}

IPF is a fatal lung disease characterized by progressive loss of lung function, dyspnea, and cough [1]. Pulmonary hypertension $(\mathrm{PH})$ is frequently found in IPF patients and is associated with an increase in the risk of death $[2,3]$.

Nintedanib (BIBF 1120) is an inhibitor of receptor tyrosine kinases, including vascular endothelial growth factor (VEGF) receptor, fibroblast growth factor (FGF) receptor, platelet-derived growth factor (PDGF) receptor, and non-receptor tyrosine kinases of the Src family

(c) The Author(s). 2019 Open Access This article is distributed under the terms of the Creative Commons Attribution 4.0 International License (http://creativecommons.org/licenses/by/4.0/), which permits unrestricted use, distribution, and 
[4]. These tyrosine kinases are involved in signaling pathways implicated in the development and progression of fibrosis [5]. The efficacy of nintedanib in idiopathic pulmonary fibrosis (IPF) patients was shown in the IMPULSIS trials and nintedanib has been approved for the treatment of IPF in several countries, including Japan [6].

In a hypoxic murine model using Sugen 5416 (SU5416), an inhibitor of the VEGF receptor, PH was exacerbated relative to hypoxic mice without SU5416 treatment [7]. Therefore, it is speculated that nintedanib, which inhibits the VEGF receptor, may adversely affect $\mathrm{PH}$ in IPF patients exposed to chronic hypoxia.

To evaluate the effect of nintedanib treatment on $\mathrm{PH}$ in IPF patients with or without oxygen therapy, this investigation included a nintedanib prospective cohort study and a historical control study, including 16 consecutive IPF patients in whom nintedanib treatment was started and 15 IPF patients without any antifibrotic therapies, respectively.

\section{Methods \\ Patient population}

IPF was diagnosed after multidisciplinary discussions in accordance with the criteria outlined by the 2011 consensus statements of the American Thoracic Society, European Respiratory Society, Japanese Respiratory Society, and Latin American Thoracic Association [8]. Among patients in the IPF cohort of the Department of Respiratory Medicine, University of Occupational and Environmental Health, Japan, between November 2015 and September 2017, IPF patients who started nintedanib treatment were enrolled in the nintedanib prospective cohort study. This prospective study was approved by the Institutional Review Board and Ethics Committee of University of Occupational and Environmental Health (IRB no: H27-180, UMIN: 000020392), and all patients provided written informed consent. We conducted a historical control study because patients with IPF usually experience the development of PH during their natural course. To match sample sizes, we used a historical control group comprising IPF patients who met the (a) and (b) criteria below from August 2008 to March 2016, retrospectively, (a) IPF patients who did not receive any antifibrotic therapies, and (b) IPF patients in whom echocardiography was performed at intervals of approximately 48 weeks. This retrospective study was approved by the Institutional Review Board and Ethics Committee of University of Occupational and Environmental Health, Japan (IRB no: 18-012).

\section{Study design}

The following characteristics were assessed at baseline: age, sex, weight, body mass index, smoking status, time since the diagnosis of IPF, long-term oxygen treatment (LTOT), arterial oxygen saturation measured by pulse oximetry $\left(\mathrm{SpO}_{2}\right)$ on room air at rest, partial pressure of arterial oxygen $\left(\mathrm{PaO}_{2}\right)$ on room air at rest, results of the pulmonary function test (forced vital capacity [FVC], forced expiratory volume in $1 \mathrm{~s}\left[\mathrm{FEV}_{1}\right]$, and diffusing capacity of the lung for carbon monoxide $\left[\mathrm{DL}_{\mathrm{CO}}\right]$ ), laboratory findings (brain natriuretic peptide [BNP]), radiographic findings (pulmonary emphysema), and comorbidities (hypertension, chronic heart failure). Dyspnea was assessed using the five-grade modified Medical Research Council (mMRC) dyspnea scale [9]. The Gender-Age-Physiology (GAP) score for IPF was also calculated in each patient, in accordance with the previously described methods [10].

In the nintedanib prospective study, pulmonary artery systolic pressure (PASP) measured using transthoracic echocardiography (TTE) and the results of pulmonary function test were evaluated at six periods (baseline, and $1,4,12,24$, and 48 weeks after starting nintedanib treatment). In the historical control study, PASP data were retrospectively collected, and annual change in PASP was adjusted to 48 weeks.

\section{Transthoracic echocardiography}

Two-dimensional TTE using color Doppler flow method was performed, including measurement of the peak tricuspid regurgitation (TR) velocity. Right atrial pressure (RAP) was estimated on the basis of the inferior vena cava size and movement with respiration, and PASP was calculated using the modified Bernoulli equation $\left(\mathrm{PASP}=4 \times \mathrm{TR}^{2}+\mathrm{RAP}\right)[11,12]$.

\section{Statistical analysis}

Data are expressed as the median [range] or number of patients (percentage). Chi-square $\left(x^{2}\right)$ tests were used to compare categorical variables. Comparisons between groups were performed using the Mann-Whitney $U$ test. Differences in PASP and FVC between baseline and assessment after 48 weeks were evaluated using a paired t-test in the nintedanib prospective study. Adjusted annual changes in PASP were assessed using a two-sample t-test in the historical control study. $P<0.05$ was considered significant. All analyses were performed using SPSS version 25 (SPSS, Inc.; Chicago, IL). MT and KO take complete responsibility for the integrity of the data and accuracy of the data analysis.

\section{Results}

The nintedanib prospective study

Patient flow schematics of the nintedanib prospective study are shown in Fig. 1a. In the nintedanib prospective study, 31 consecutive IPF patients were enrolled, of which 15 patients failed to continue nintedanib 
a IPF patients started treatment with nintedanib: $\mathrm{n}=31$

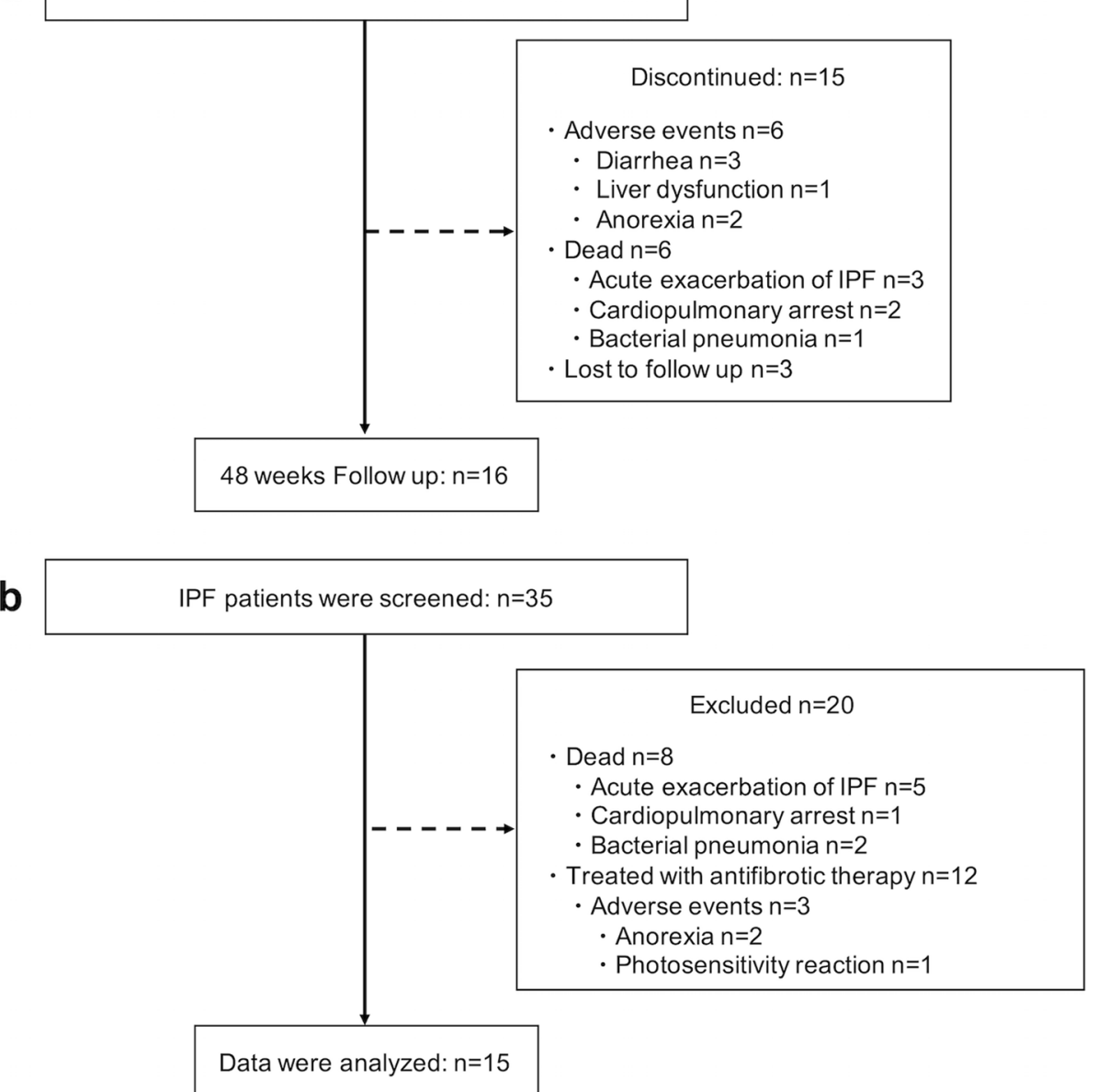

Fig. 1 Patient flow diagrams of nintedanib prospective and historical control studies. a In the nintedanib prospective study, 31 consecutive idiopathic pulmonary fibrosis (IPF) patients were enrolled. Fifteen patients failed to continue nintedanib treatment for 48 weeks for various reasons (adverse events, $n=6$; death, $n=6$; lost to follow-up, $n=3$ ). Follow-up studies were available in 16 patients at 48 weeks. $\mathbf{b}$ In the historical control study, 35 consecutive IPF patients were screened retrospectively. Of these patients, 20 IPF patients were excluded for some reason (poor quality echocardiography, $n=8$; treated with anti-fibrotic therapy, $n=12$ ). Finally, 15 IPF patients who did not receive any anti-fibrotic therapies were analyzed

treatment for 48 weeks, resulting in 16 patients available for the follow-up studies at 48 weeks (Fig. 1a).

The baseline characteristics of the 16 patients in the nintedanib prospective study are shown in Table 1 . The median age was 71 years old, $88 \%$ were male, and the median \%FVC predicted was $62 \%$. Nine IPF patients received LTOT and seven IPF patients did not receive LTOT. Compared with IPF patients without LTOT, IPF patients with LTOT had significantly decreased $\mathrm{DL}_{\mathrm{CO}}$ (\% predicted) $(P=0.017)$ and relatively lower $\mathrm{PaO}_{2}$ on room air at rest, but the difference was not significant $(p=0.054)$. Among IPF patients without LTOT, none started LTOT during the study period.

Figure 2 shows the values of the mean changes in PASP (a) and FVC (b) from baseline in the nintedanib prospective study. The value of the mean changes in
PASP gradually increased and compared to baseline, PASP was significantly higher 48 weeks after nintedanib treatment $(P=0.001)$ (Fig. 2a). The mean value of changes in FVC gradually decreased and was significantly lower 48 weeks after nintedanib treatment compared with baseline $(P=0.021)$ (Fig. $2 b)$. Figure 3 shows the difference in the values of the mean changes in PASP (a) and FVC (b) from baseline between IPF patients with (solid line) and without LTOT (dotted line). The values of the mean PASP changes 48 weeks after nintedanib treatment in IPF patients with (solid line) and without (dotted line) LTOT were $8.24 \mathrm{mmHg}$ and $2.84 \mathrm{mmHg}$, respectively. A significant increase in the value of the mean PASP from baseline was observed 48 weeks after nintedanib in IPF patients with LTOT $(P=$ 0.001) (Fig. 3a). There were no significant decreases in 
Table 1 Baseline characteristics of patients in nintedanib prospective study

\begin{tabular}{|c|c|c|c|c|}
\hline & $\begin{array}{l}\text { Nintedanib } \\
(n=16)\end{array}$ & $\begin{array}{l}\text { Nintedanib with LTOT } \\
(n=9)\end{array}$ & $\begin{array}{l}\text { Nintedanib without LTOT } \\
(n=7)\end{array}$ & $P$ value \\
\hline Age (years) & $71[57-80]$ & $69[57-77]$ & $73[64-80]$ & 0.536 \\
\hline Male & $14(88 \%)$ & $8(88 \%)$ & $6(86 \%)$ & 0.849 \\
\hline Weight (kg) & $61.0[43.3-73.9]$ & $68.7[43.3-73.9]$ & $59.6[44.3-61.5]$ & 0.055 \\
\hline Body mass index & $24.2[15.1-26.9]$ & $25.1[15.1-26.9]$ & $22.0[19.0-26.7]$ & 0.210 \\
\hline \multicolumn{5}{|l|}{ Smoking status } \\
\hline Never / Former / Current smoker & $1 / 15 / 0$ & $0 / 9 / 0$ & $0 / 7 / 0$ & - \\
\hline Time since the diagnosis of IPF (years) & $4[0-9]$ & $2[0-9]$ & $4[1-8]$ & 0.408 \\
\hline Long-term oxygen treatment & $9(56 \%)$ & - & - & - \\
\hline mMRC dyspnea scale & $2[0-3]$ & $3[0-3]$ & $1[0-2]$ & 0.114 \\
\hline GAP score & $4[2-8]$ & $5[2-8]$ & $4[3-5]$ & 0.174 \\
\hline $\mathrm{SpO}_{2}$ on room air at rest (\%) & 96 [94-99] & 95 [94-97] & 97 [94-99] & 0.234 \\
\hline $\mathrm{PaO}_{2}$ on room air at rest $(\mathrm{mmHg})$ & $83[59-122]$ & 75 [59-94] & $88[81-122]$ & 0.054 \\
\hline PASP measured by TTE at baseline (mmHg) & $34.0[21.0-59.0]$ & $33.0[21.0-59.0]$ & $35.0[27.6-55.3]$ & 1.000 \\
\hline \multicolumn{5}{|l|}{ Pulmonary function tests } \\
\hline $\mathrm{FVC}(\mathrm{mL})$ & $1.930[1.060-3030]$ & $2.140[1.060-3.030]$ & $1.840[1.540-2.690]$ & 0.408 \\
\hline FVC (\% predicted) & $62[28-88]$ & 66 [28-88] & $57[51-79]$ & 0.758 \\
\hline $\mathrm{FEV}_{1}(\mathrm{~mL})$ & $1.700[1.030-2.470]$ & $1.990[1.030-2.407]$ & $1.560[1.330-2.270]$ & 0.536 \\
\hline $\mathrm{FEV}_{1}(\%$ predicted $)$ & 68 [34-91] & 67 [34-91] & $76[50-81]$ & 0.758 \\
\hline $\mathrm{DL}_{\mathrm{CO}}(\mathrm{mL} / \mathrm{min} / \mathrm{mmHg})$ & $10.2[5.1-18.6]$ & $8.3[5.1-13.6]$ & $10.7[8.1-18.6]$ & 0.209 \\
\hline $\mathrm{DL}_{\mathrm{CO}}(\%$ predicted $)$ & $70[30-91]$ & $49[30-76]$ & $70[48-91]$ & 0.017 \\
\hline \multicolumn{5}{|l|}{ Laboratory findings } \\
\hline BNP & $31.6[7.6-1.313]$ & $28.4[7.6-1.313]$ & $27.2[10.0-53.9]$ & 0.837 \\
\hline \multicolumn{5}{|l|}{ Radiographic findings } \\
\hline Pulmonary emphysema & $6(38 \%)$ & $5(56 \%)$ & $1(14 \%)$ & 0.121 \\
\hline \multicolumn{5}{|l|}{ Comorbidity } \\
\hline Hypertension & $6(38 \%)$ & $3(33 \%)$ & $3(43 \%)$ & 0.696 \\
\hline Chronic heart failure & $0(0 \%)$ & $0(0 \%)$ & $0(0 \%)$ & - \\
\hline
\end{tabular}

Data are presented as median [range] or number of patients (percentage)

IPF idiopathic pulmonary fibrosis, LTOT long-term oxygen treatment, $m M R C$ modified Medical Research Council, GAP Gender-Age-Physiology, SpO ${ }_{2}$ arterial oxygen saturation measured by pulse oximetry, $\mathrm{PaO}_{2}$ partial pressure of arterial oxygen, $P A S P$ pulmonary artery systolic pressure, $T E$ transthoracic echocardiography, $F V C$ forced vital capacity, $F E V_{1}$ forced expiratory volume in $1 \mathrm{~s}, D L_{c o}$ diffusing capacity of the lung for carbon monoxide, $B N P$ brain natriuretic peptide $P$ value: nintedanib with LTOT vs nintedanib without LTOT

the value of mean FVC compared to baseline in either group $(P=0.188$ and $P=0.314)$ (Fig. 3b).

\section{The historical control study}

Figure $1 \mathrm{~b}$ demonstrates the patient flow schematics of the historical control study. A total of 35 consecutive IPF patients were retrospectively screened, and 20 IPF patients were excluded. Finally, 15 IPF patients without any antifibrotic medications were evaluated (Fig. 1b).

Table 2 shows the baseline characteristics of patients treated with nintedanib (the nintedanib group) and those treated with any antifibrotic therapy (the no antifibrotic therapy group) in the historical control study. Among IPF patients with LTOT, the nintedanib group consisted of nine patients and 10 patients were categorized in the no antifibrotic therapy group. Regarding the IPF patients without LTOT, seven patients were in the nintedanib group and five patients were in the no antifibrotic therapy group. Among IPF patients with and without LTOT, there were no significant differences in characteristics between the nintedanib group and no antifibrotic therapy group. Figure 4 shows the comparison of adjusted annual change in PASP between the nintedanib and no antifibrotic therapy groups in IPF patients with and without LTOT. There were no significant differences between the nintedanib and no antifibrotic therapy groups (7.19 $\mathrm{mmHg}$ vs $6.48 \mathrm{mmHg} ; P=0.800$ ) in IPF patients with LTOT. Conversely, among IPF patients without 


\section{a Mean Observed Change from Baseline in PASP $(\mathrm{mmHg})$}

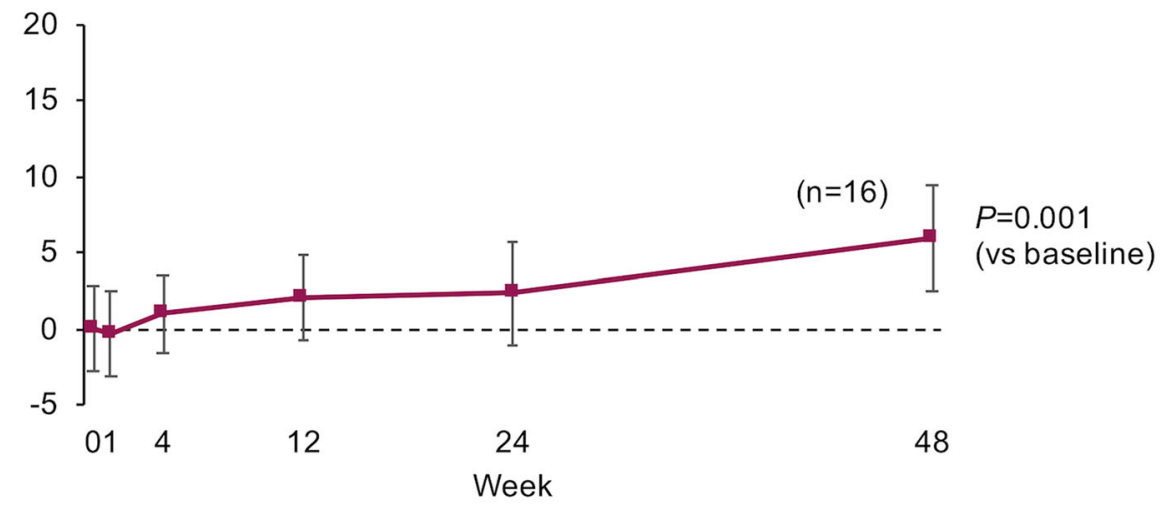

b Mean Observed Change from Baseline in FVC (ml)

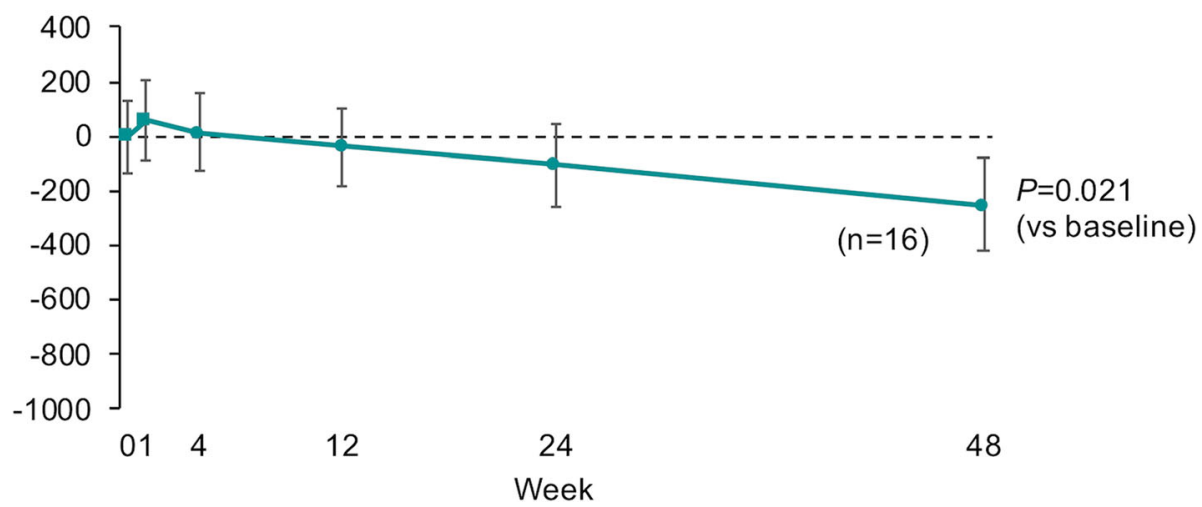

Fig. 2 Mean observed change from baseline in PASP and FVC in nintedanib prospective study. a The mean observed change from baseline in pulmonary artery systolic pressure (PASP) after starting nintedanib treatment. The value of the mean changes in PASP gradually increased and PASP was significantly higher at 48 weeks after nintedanib treatment than at baseline $(P=0.001)$. b The mean value of changes in forced vital capacity (FVC) gradually decreased and were significantly lower at 48 weeks after nintedanib treatment than at baseline $(P=0.021)$. Changes in mean PASP and FVC from baseline to 48 weeks after treatment were assessed using a paired t-test. Two-sided $P$-values 0.05 were considered significant

LTOT, the adjusted annual change in PASP was significantly lower in the nintedanib group than in the no antifibrotic therapy group $(0.26 \mathrm{mmHg}$ vs 7.05 mmHg; $P=0.011$ ). There were no significant differences in the adjusted annual change in FVC between the nintedanib and no antifibrotic therapy groups in IPF patients with and without LTOT (see Additional file 1).

\section{Discussion}

This study is the first prospective echocardiographic assessment of $\mathrm{PH}$ after starting nintedanib treatment in IPF patients with or without LTOT. Our prospective study compared the effects of nintedanib in IPF patients with or without LTOT and showed that PASP at 48 weeks after starting nintedanib in IPF patients with LTOT was significantly increased, but not in IPF patients without LTOT (Fig. 3a). Additionally, our retrospective study demonstrated that adjusted annual change of PASP in IPF patients without LTOT treated with nintedanib was unchanged or decreased but adjusted annual change of PASP in IPF patients with LTOT treated with nintedanib was similar to that in patients without antifibrotic agents (Fig. 4). Collectively, nintedanib might cause deterioration of $\mathrm{PH}$ in hypoxic IPF patients; conversely, nintedanib may prevent $\mathrm{PH}$ in normoxic IPF patients. Our results may suggest that physicians should be aware of a deterioration in $\mathrm{PH}$ after starting nintedanib in IPF patients with LTOT or hypoxic IPF patients. In addition, nintedanib treatment may possibly be beneficial in IPF patients before developing severe respiratory failure.

Adverse effects of nintedanib on $\mathrm{PH}$ in hypoxic IPF patients may partly be explained by the finding that exacerbation of severe $\mathrm{PH}$ was observed in hypoxic mice treated with a selective inhibitor of VEGF-2 receptor (SU5416) in comparison with hypoxic control mice without SU5416 treatment [7]. At least as a VEGF-2 receptor inhibitor, nintedanib treatment in hypoxic IPF 


\section{a} Mean Observed Change from Baseline in PASP $(\mathrm{mmHg})$
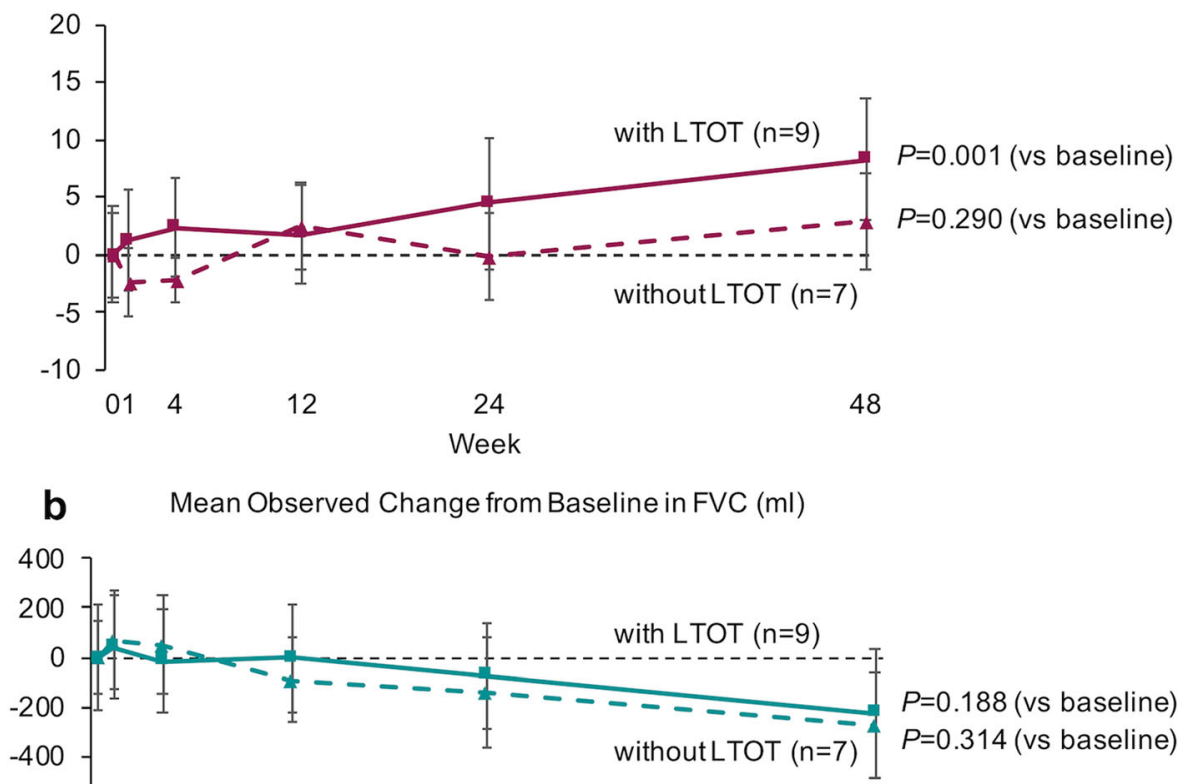

$-800$ $-1000$

$01412 \quad 24$

Week

Fig. 3 Mean observed change in PASP and FVC between IPF patients with LTOT and without LTOT. a The values of mean pulmonary artery systolic pressure (PASP) changes after nintedanib treatment in idiopathic pulmonary fibrosis (IPF) patients with (solid line) and without (dotted line) long-term oxygen treatment (LTOT). Mean PASP increases were $8.24 \mathrm{mmHg}$ and $2.84 \mathrm{mmHg}$, respectively. There was a significant increase in the value of the mean PASP 48 weeks after nintedanib relative to baseline in IPF patients with LTOT $(P=0.001)$. $\mathbf{b}$ The values of mean forced vital capacity (FVC) changes after nintedanib treatment in IPF patients with (solid line) and without (dotted line) LTOT. mean FVC decreases were 224 $\mathrm{mL}$ and $270 \mathrm{~mL}$, respectively. There were no significant decreases in the mean FVC relative to baseline in either group $(P=0.188$ and $P=0.314)$. Changes in the value of the mean PASP and FVC from baseline to 48 weeks after nintedanib treatment were assessed using a paired t-test. Twosided $P$-values $<0.05$ were considered significant

patients may possibly lead to similar consequences as seen in this hypoxic animal model. Several studies have reported poor adherence to oxygen therapy in chronic respiratory diseases $[13,14]$, and patients with LTOT may frequently be exposed to hypoxia during exercise. Similarly, IPF patients with LTOT may frequently be exposed to hypoxia in our study. Therefore, treating hypoxic IPF patients with nintedanib might provoke PH in IPF patients with LTOT. In fact, Shimomura et al. have reported PH can be exacerbated by nintedanib administration in IPF patients with comorbid chronic hypoxia [15].

The protective effects of nintedanib on $\mathrm{PH}$ in normoxic IPF patients have been unclear so far, but a recent report evaluating the effect of nintedanib on the proliferation of human pulmonary microvascular endothelial cells (MVEC) in a rat PH model showed that nintedanib itself might have protective effects against right ventricular hypertrophy [16]. In this report, VEGF-induced proliferation of control MVECs obtained from control patients was reduced by nintedanib, and nintedanib inhibited VEGF-stimulated phosphorylation of ERK1/2 in a dose dependent manner [16]. In an SU5416-induced PH rat model that was firstly exposed to $10 \%$ hypoxia for four weeks and then four weeks of exposure to normoxia, subsequent normoxic nintedanib treatment demonstrated less dilatation, and decreased fibrosis and hypertrophy with decreased collagen deposition in the right ventricle [16]. This could be partly explained by the reduced fibronectin production of cardiac fibroblasts exposed to nintedanib [16]. In addition, the prophylactic effects of nintedanib on the natural progression of pulmonary fibrosis may also prevent deterioration of PH in IPF patients, and collectively, nintedanib may prevent exacerbation of $\mathrm{PH}$ in normoxic IPF patients. Future investigations are needed to reveal the comprehensive mechanisms of the effects of nintedanib on $\mathrm{PH}$.

Several limitations of this study should be addressed. First, this was a single-centre study with a relatively small sample size. Second, the nintedanib 
Table 2 Baseline characteristics between the nintedanib group and no antifibrotic therapy group in historical control study

\begin{tabular}{|c|c|c|c|c|c|c|}
\hline & \multicolumn{2}{|c|}{ IPF patients with LTOT $(n=19)$} & \multirow{3}{*}{$\begin{array}{l}P \\
\text { value }\end{array}$} & \multicolumn{2}{|c|}{ IPF patients without LTOT $(n=12)$} & \multirow{3}{*}{$\begin{array}{l}P \\
\text { value }\end{array}$} \\
\hline & Nintedanib & $\begin{array}{l}\text { No antifibrotic } \\
\text { therapy }\end{array}$ & & \multirow{2}{*}{$\begin{array}{l}\text { Nintedanb } \\
(n=7)\end{array}$} & \multirow{2}{*}{$\begin{array}{l}\text { No antifibrotic } \\
\text { therapy } \\
(n=5)\end{array}$} & \\
\hline & $(n=9)$ & $(n=10)$ & & & & \\
\hline Age (years) & $69[57-77]$ & $72[60-83]$ & 0.315 & $73[64-80]$ & $70[48-76]$ & 0.639 \\
\hline Male & $8(88 \%)$ & $6(60 \%)$ & 0.153 & $6(86 \%)$ & $4(80 \%)$ & 0.793 \\
\hline Weight (kg) & $68.7[43.3-73.9]$ & $54.7[26.0-72.0]$ & 0.065 & $59.6[44.3-61.5]$ & $52.9[46.9-63.0]$ & 0.876 \\
\hline Body mass index & $25.1[15.1-26.9]$ & $20.2[13.7-28.8]$ & 0.661 & $22.0[19.0-26.7]$ & $20.7[18.6-26.7]$ & 0.876 \\
\hline \multicolumn{7}{|l|}{ Smoking status } \\
\hline Never / Former / Current smoker & $0 / 9 / 0$ & $3 / 7 / 0$ & - & $0 / 7 / 0$ & $1 / 4 / 0$ & - \\
\hline Time since the diagnosis of IPF (years) & $2[0-9]$ & $1[0-3]$ & 0.400 & $4[1-8]$ & $3[0-4]$ & 0.202 \\
\hline mMRC dyspnea scale & $3[0-3]$ & $2[1-3]$ & 0.842 & $1[0-2]$ & $2[0-3]$ & 0.343 \\
\hline GAP score & $5[2-8]$ & $5[1-7]$ & 0.796 & $4[3-5]$ & $5[2-5]$ & 0.648 \\
\hline $\mathrm{SpO}_{2}$ on room air at rest (\%) & 95 [94-97] & 95 [89-98] & 0.573 & 97 [94-99] & 96 [95-98] & 0.648 \\
\hline $\mathrm{PaO}_{2}$ on room air at rest $(\mathrm{mmHg})$ & 75 [59-94] & 70 [47-89] & 0.277 & $88[81-122]$ & 91 [75-103] & 0.927 \\
\hline PASP measured by TTE at baseline $(\mathrm{mmHg})$ & $33.0[21.0-59.0]$ & $41.4[31-56.2]$ & 0.278 & $35.0[27.6-55.3]$ & $37.0[27.9-56.2]$ & 0.775 \\
\hline \multicolumn{7}{|l|}{ Pulmonary function tests } \\
\hline $\mathrm{FVC}(\mathrm{mL})$ & $\begin{array}{l}2.140[1.060- \\
3.030]\end{array}$ & $1.735[1.170-2.480]$ & 0.278 & $\begin{array}{l}1.840[1.540- \\
2.690]\end{array}$ & $2.020[1.060-2.370]$ & 0.953 \\
\hline FVC (\% predicted) & 66 [28-88] & $61[46-74]$ & 0.720 & $57[51-79]$ & $64[35-73]$ & 0.530 \\
\hline $\mathrm{FEV}_{1}(\mathrm{~mL})$ & $\begin{array}{l}1.990[1.030- \\
2.407]\end{array}$ & $1.560[1.010-2.280]$ & 0.356 & $\begin{array}{l}1.560[1.330- \\
2.270]\end{array}$ & $1.930[1.050-2.100]$ & 1.000 \\
\hline $\mathrm{FEV}_{1}(\%$ predicted $)$ & 67 [34-91] & $72[56-83]$ & 0.549 & $76[50-81]$ & $73[40-85]$ & 0.876 \\
\hline $\mathrm{DL}_{\mathrm{CO}}(\mathrm{mL} / \mathrm{min} / \mathrm{mmHg})$ & $8.3[5.1-13.6]$ & $6.6[4.3-11.7]$ & 0.091 & $10.7[8.1-18.6]$ & $10.0[7.3-16.3]$ & 0.788 \\
\hline $\mathrm{DL}_{\mathrm{CO}}(\%$ predicted $)$ & $49[30-76]$ & 40 [29-73] & 0.299 & 70 [48-91] & 74 [38-129] & 1.000 \\
\hline \multicolumn{7}{|l|}{ Radiographic findings } \\
\hline Pulmonary emphysema & $5(56 \%)$ & $3(30 \%)$ & 0.414 & $1(14 \%)$ & $1(20 \%)$ & 0.682 \\
\hline \multicolumn{7}{|l|}{ Comorbidity } \\
\hline Hypertension & $3(33 \%)$ & $4(40 \%)$ & 0.764 & $3(43 \%)$ & $1(20 \%)$ & 0.408 \\
\hline Chronic heart failure & $0(0 \%)$ & $0(0 \%)$ & - & $0(0 \%)$ & $0(0 \%)$ & - \\
\hline \multicolumn{7}{|l|}{ No antifibrotic agent } \\
\hline No treatment & - & $3(30 \%)$ & - & - & $1(20 \%)$ & - \\
\hline Corticosteroid monotherapy & - & $1(10 \%)$ & - & - & $2(40 \%)$ & - \\
\hline $\begin{array}{l}\text { Combined corticosteroid and immunomodulator } \\
\text { therapy }\end{array}$ & - & $5(50 \%)$ & - & - & $2(40 \%)$ & - \\
\hline Inhalation of $\mathrm{N}$-acetyl-cysteine & - & $1(10 \%)$ & - & - & $0(0 \%)$ & - \\
\hline
\end{tabular}

Data are presented as median [range] or number of patients (percentage)

IPF idiopathic pulmonary fibrosis, LTOT long-term oxygen treatment, $m M R C$ modified Medical Research Council, GAP Gender-Age-Physiology, SpO ${ }_{2}$ arterial oxygen saturation measured by pulse oximetry, $\mathrm{PaO}_{2}$ partial pressure of arterial oxygen, $P A S P$ pulmonary artery systolic pressure, $T T E$ transthoracic echocardiography, $F V C$ forced vital capacity, $F E V$ forced expiratory volume in $1 \mathrm{~s}, D L_{C O}$ diffusing capacity of the lung for carbon monoxide $P$ value: the nintedanib group vs the no antifibrotic therapy group

prospective study only included patients treated with nintedanib, and no control arm was conducted. However, a historical control was used as a control arm similar to a previous study [17]. In addition, we regularly perform TTE at least once a year to detect the early onset and deterioration of $\mathrm{PH}$ in all patients with interstitial pneumonia, including IPF. Therefore, we think that this selection bias of performing echocardiography in the historical control group may be minimal. Third, we could not evaluate right heart catheter testing. Fourth, the tricuspid annular plane systolic excursion, tissue doppler imaging systolic wall motion velocity, and Tei index in echocardiographic assessment were not included because high-quality $\mathrm{RV}$-focused images were not obtained from IPF patients in our study. 


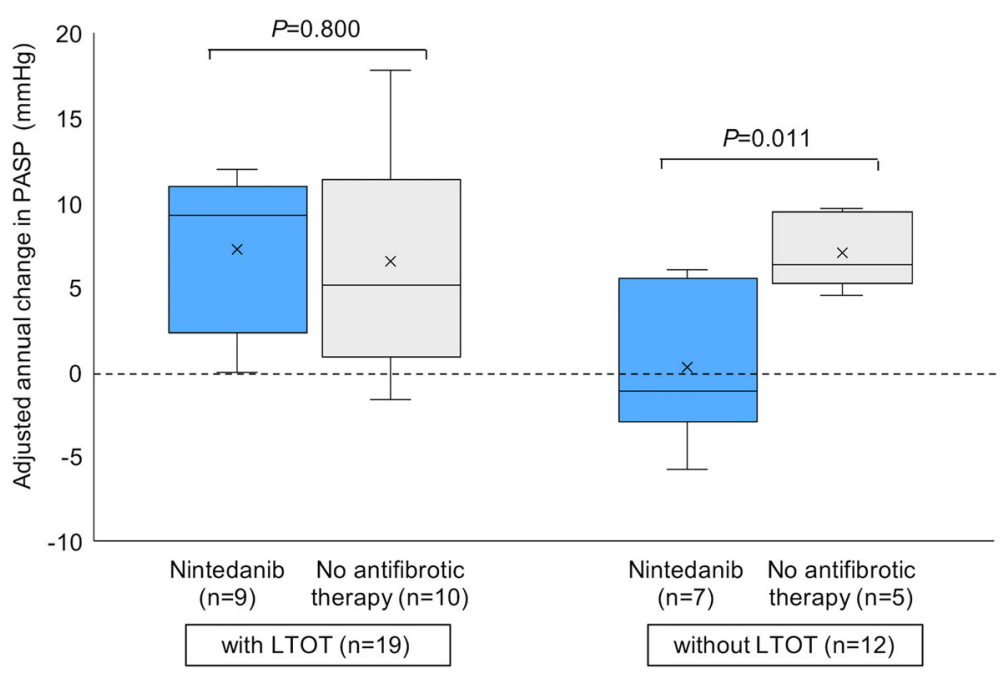

Fig. 4 Comparison of adjusted annual change in PASP in historical control study. Comparison of adjusted annual changes in pulmonary artery systolic pressure (PASP) between the nintedanib groups and no antifibrotic therapy groups in idiopathic pulmonary fibrosis (IPF) patients with long-term oxygen treatment (LTOT) (left) and without LTOT (right). There were no significant differences between the nintedanib and no antifibrotic therapy groups $(7.19 \mathrm{mmHg}$ vs $6.48 \mathrm{mmHg}$; $=0.800)$ in IPF patients with LTOT. Conversely, among IPF patients without LTOT, the adjusted annual change in PASP was significantly lower in the nintedanib group than in the no antifibrotic therapy group $(0.26 \mathrm{mmHg}$ vs 7.05 $\mathrm{mmHg} ; P=0.011$ ). Adjusted annual change in PASP was assessed using a two-sample t-test. Two-sided $P$-values $<0.05$ were considered significant

\section{Conclusions}

We examined the differential effects of nintedanib on $\mathrm{PH}$ between IPF patients with or without LTOT in this temporal echocardiographic assessment. Nintedanib may have a disadvantageous effect on PH in IPF patients with LTOT. Conversely, nintedanib treatment may also be beneficial to PH in IPF patients without LTOT. Accordingly, early nintedanib treatment might be more beneficial than starting with hypoxia in IPF patients with respiratory failure. Prospective randomized placebo-controlled trials are expected to elucidate proper nintedanib treatment in terms of protecting progression of $\mathrm{PH}$ in IPF patients.

\section{Additional file}

Additional file 1: Comparison of adjusted annual change in FVC in historical control study. Comparison of adjusted annual changes in forced vital capacity (FVC) between the nintedanib group and no antifibrotic therapy group in idiopathic pulmonary fibrosis (IPF) patients with longterm oxygen treatment (LTOT) (left) and without LTOT (right). There were no significant differences in the adjusted annual change between the nintedanib and no antifibrotic therapy groups in IPF patients with and without LTOT. Adjusted annual change in FVC was assessed using a twosample t-test. Two-sided $P$ values of $<0.05$ were considered significant. (TIFF $9067 \mathrm{~kb}$ ) pressure; TR: Tricuspid regurgitation; TTE: Transthoracic echocardiography; VEGF: Vascular endothelial growth factor

\section{Acknowledgements}

The authors would like to thank Drs. Masaaki Takeuchi and Yamato Yoshida (Department of Laboratory and Transfusion Medicine, Hospital of University of Occupational and Environmental Health, School of Medicine, Japan) for useful discussion and their technical assistances.

\section{Authors' contributions}

$\mathrm{MT}, \mathrm{KO}$ and $\mathrm{KY}$ made substantial contributions to the conception and design of the study. MT, KO, KT and KS acquired the data. MT and $\mathrm{KO}$ analyzed and interpreted the data. MT, KO, KY, SN, NS, TK, HM and KY participated in drafting the article and critically revising it for important intellectual content. All authors have read and approved the final manuscript.

\section{Funding}

Not applicable

\section{Availability of data and materials}

The datasets used for the current study are available from the corresponding author on reasonable request.

\section{Ethics approval and consent to participate}

The prospective study was approved by the Institutional Review Board and Ethics Committee of University of Occupational and Environmental Health (IRB no: H27-180, UMIN: 000020392), and all patients provided written informed consent. The retrospective study was approved by the Institutional Review Board and Ethics Committee of University of Occupational and Environmental Health, Japan (IRB no: 18-012).

\section{Consent for publication}

Not applicable

\section{Competing interests}

The authors declare that they have no competing interests. 


\section{Author details}

'Department of Respiratory Medicine, University of Occupational and Environmental Health, Japan, 1-1 Iseigaoka, Yahatanishiku, Kitakyushu city, Fukuoka 807-8555, Japan. ${ }^{2}$ Department of Respiratory Medicine, Nagasaki University Graduate School of Biomedical Sciences, 1-7-1 Sakamoto, Nagasaki city, Nagasaki 852-8501, Japan.

Received: 22 March 2019 Accepted: 12 August 2019

Published online: 22 August 2019

\section{References}

1. American Thoracic Society. Idiopathic pulmonary fibrosis: diagnosis and treatment. International consensus statement. American Thoracic Society (ATS), and the European Respiratory Society (ERS). Am J Respir Crit Care Med. 2000;161:646-64.

2. Patel NM, Lederer DJ, Borczuk AC, Kawut SM. Pulmonary hypertension in idiopathic pulmonary fibrosis. Chest. 2007;132:998-1006.

3. Lettieri CJ, Nathan SD, Barnett SD, Ahmad S, Shorr AF. Prevalence and outcomes of pulmonary arterial hypertension in advanced idiopathic pulmonary fibrosis. Chest. 2006;129:746-52.

4. Hilberg F, Roth GJ, Krssak M, Kautschitsch S, Sommergruber W, TontschGrunt U, et al. BIBF 1120: triple angiokinase inhibitor with sustained receptor blockade and good antitumor efficacy. Cancer Res. 2008;68:4774-82.

5. Grimminger $F$, Gunther $A$, Vancheri $C$. The role of tyrosine kinases in the pathogenesis of idiopathic pulmonary fibrosis. Eur Respir J. 2015;45:1426-33.

6. Richeldi L, du Bois RM, Raghu G, Azuma A, Brown KK, Costabel U, et al. Efficacy and safety of nintedanib in idiopathic pulmonary fibrosis. N Engl J Med. 2014;370:2071-82.

7. Taraseviciene-Stewart L, Kasahara Y, Alger L, Hirth P, Mc Mahon G, Waltenberger J, et al. Inhibition of the VEGF receptor 2 combined with chronic hypoxia causes cell death-dependent pulmonary endothelial cell proliferation and severe pulmonary hypertension. FASEB J. 2001;15:427-38.

8. Raghu G, Rochwerg B, Zhang Y, Garcia CA, Azuma A, Behr J, et al. American Thoracic Society, European Respiratory Society, Japanese Respiratory Society, Latin American Thoracic Association. An official ATS/ERS/JRS/ALAT clinical practice guideline: treatment of idiopathic pulmonary fibrosis. An update of the 2011 clinical practice guideline. Am J Respir Crit Care Med. 2015;192:e3-19.

9. Mahler DA, Wells CK. Evaluation of clinical methods for rating dyspnea. Chest. 1988;93:580-6.

10. Ley B, Ryerson CJ, Vittinghoff E, Ryu JH, Tomassetti S, Lee JS, et al. A multidimensional index and staging system for idiopathic pulmonary fibrosis. Ann Intern Med. 2012;156:684-91.

11. Currie PJ, Seward JB, Chan KL, Fyfe DA, Hagler DJ, Mair DD, et al. Continuous wave Doppler determination of right ventricular pressure: a simultaneous Doppler-catheterization study in 127 patients. J Am Coll Cardiol. 1985;6:750-6.

12. Kircher BJ, Himelman RB, Schiller NB. Noninvasive estimation of right atrial pressure from the inspiratory collapse of the inferior vena cava. Am J Cardiol. 1990;66:493-6.

13. Ringbaek T, Lange P, Viskum K. Compliance with LTOT and consumption of mobile oxygen. Respir Med. 1999;93:333-7.

14. Gauthier A, Bernard S, Bernard E, Simard S, Maltais F, Lacasse Y. Adherence to long-term oxygen therapy in patients with chronic obstructive pulmonary disease. Chron Respir Dis. 2019. https://doi.org/10.1177/14 79972318767724.

15. Shimomura I, Abe M, Li Y, Tsushima K, Sakao S, Tanabe N, et al. Pulmonary Hypertension Exacerbated by Nintedanib Administration for Idiopathic Pulmonary Fibrosis. Intern Med. 2018. https://doi.org/10.2169/ internalmedicine.1384-18.

16. Rol N, de Raaf MA, Sun X, Kuiper VP, da Silva Goncalves Bos D, Happe C, et al. Nintedanib improves cardiac fibrosis but leaves pulmonary vascular remodeling unaltered in experimental pulmonary hypertension. Cardiovasc Res. 2019. https://doi.org/10.1093/cvr/cvy186.

17. Kataoka K, Taniguchi H, Kondoh Y, Nishiyama O, Kimura T, Matsuda T, et al. Recombinant human thrombomodulin in acute exacerbation of idiopathic pulmonary fibrosis. Chest. 2015;148:436-43.

\section{Publisher's Note}

Springer Nature remains neutral with regard to jurisdictional claims in published maps and institutional affiliations.

Ready to submit your research? Choose BMC and benefit from:

- fast, convenient online submission

- thorough peer review by experienced researchers in your field

- rapid publication on acceptance

- support for research data, including large and complex data types

- gold Open Access which fosters wider collaboration and increased citations

- maximum visibility for your research: over $100 \mathrm{M}$ website views per year

At BMC, research is always in progress.

Learn more biomedcentral.com/submissions 